\title{
Distance Between the Tumour and Nipple as a Predictor of Axillary Lymph Node Involvement in Breast Cancer
}

This article was published in the following Dove Press journal: Cancer Management and Research

\author{
Jiqiao Yang ${ }^{1,2, *}$ \\ Qianru Yangl,* \\ Arjudeb Mukherjee ${ }^{3}$ \\ Qing Lv ID' \\ 'Department of Breast Surgery, West \\ China Hospital, Sichuan University, \\ Chengdu, 61004I, People's Republic of \\ China; ${ }^{2}$ Clinical Research Center for \\ Breast Disease, West China Hospital, \\ Sichuan University and Collaborative \\ Innovation Center, Chengdu, 61004I, \\ People's Republic of China; ${ }^{3}$ West China \\ School of Medicine/West China Hospital, \\ Sichuan University, Chengdu 61004I, \\ People's Republic of China
}

*These authors contributed equally to this work
Correspondence: Qing Lv Department of Breast Surgery, West China Hospital, Sichuan University, Guoxuexiang 37, Chengdu 61004I, People's Republic of China Tel +86-1898060I462

Email Ivqingwestchina@163.com
Purpose: The possibility of axillary node metastasis via the lymphatics might be related to a cancer's location within the breast. Previous studies of this topic had small sample sizes, inaccuracies because of subjective differences, and the inability to depict the entire threedimensional structure of the breast. Here, we aimed to improve upon these existing drawbacks by retrospectively analysing whether tumour location (quadrants) and tumour-nipple distance can predict axillary node positivity.

Patients and Methods: We identified 961 patients with invasive breast cancer between January 2000 and April 2016. The tumour-nipple distance was objectively measured intraoperatively and clinicopathological information was extracted from hospital database. The distance was measured radially from the nipple to the epicentre rather than the edge of tumour to obviate confounders resulting from tumour size variations.

Results: A total of 847 breast cancers ( 839 patients) met the eligibility criteria and were included in the statistical analysis. The tumour-nipple distance was smaller in node-positive patients $(\mathrm{n}=307 ; 2.76 \pm 2.07 \mathrm{~cm})$ than in node-negative patients $(\mathrm{n}=297 ; 3.41 \pm 2.18 \mathrm{~cm})$ $(p<0.001)$. Tumour-nipple distance was an independent predictor of axillary involvement on logistic regression analysis. However, no statistically significant relationship was detected between node positivity and breast quadrant tumour location.

Conclusion: Tumour-nipple distance can be used to predict axillary lymph node metastasis and assist in surgical decision-making and therapy planning. However, exploratory studies are required to increase our understanding of the mechanism.

Keywords: axillary lymph node metastasis, breast cancer, tumour location, tumour-nipple distance

\section{Introduction}

Axillary lymph node status is a crucial prognostic factor and essential for surgical decision-making, reconstructive options, and adjuvant therapy planning for breast cancer patients. ${ }^{1,2}$ However, the need for axillary lymph node dissection has decreased since the emergence of sentinel lymph node biopsy. ${ }^{3}$

The superficial lymphatic drainage of the breast is richly scattered from the skin to a depth of $3 \mathrm{~mm} .{ }^{4,5}$ The axillary or lateral pathway of the breast lymphatic drainage is fed by Sappey's plexus, ducts satellite lymphatics, and most of the parenchymal lymphatics interacting with the internal mammary pathway and retromammary pathway, hinting at the possibility that metastasis to the axillary node via the lymphatics might be related to tumour location. ${ }^{6}$ However, the comprehensive 
lymphatic anatomy of the breast remains to be elucidated and the association between axillary nodal metastasis and tumour location remains undetermined.

To, only a few clinical studies have focused on the association between axillary node metastasis and breast cancer location as well as the distance between the tumour and the nipple or skin's surface. Previous reports were inconclusive and had drawbacks. First, the sample sizes were relatively small. Second, the distance from the tumour to the nipple was measured indirectly on imaging. When an ultrasound examination is performed, the pressure applied by the probe might result in a smaller than actual measured distance. ${ }^{7}$ It is worth mentioning that probe pressure varies among operators. In certain studies, adjustments were mandatory to reduce reader-associated bias. ${ }^{8}$ These subjective differences may hamper examination precision and reproducibility. For mammography, the fluorescence figure could only reveal a distance on the mediolateral oblique or craniocaudal views, which do not depict the entire picture of the three-dimensional breast structure. With regard to magnetic resonance imaging (MRI), similar limitations as well as patient position (prone)-related biases exist.

Therefore, to overcome the shortcomings of existing reports, this study aimed to retrospectively analyse breast cancer tumour location by quadrant and tumour-nipple distance to attempt to predict axillary lymph node involvement using objective pathological data.

\section{Patients and Methods}

\section{Patient Selection}

From the hospital database, we retrospectively identified 961 patients who were pathologically diagnosed with invasive breast cancer and treated at West China Hospital, Sichuan University, between January 2000 and April 2016. Patients whose tumours were palpable or visible during surgery were included. Accordingly, the following exclusion criteria were applied: 1) male sex; 2) unavailability of axillary surgical staging; 3) receipt of radiotherapy, endocrine therapy, or neoadjuvant chemotherapy before surgery and axillary staging; 4) presence of multifocal or multicentric tumours; 5) recurrent cancer or prior history of breast cancer; 6) prior history of surgery in the affected breast (for benign lesions or cosmetic purposes); 7) Paget's disease; 8) skin or chest wall involvement; and 9) presence of metastasis at diagnosis.

The clinicopathological data collected for each patient included the following: sex; date of birth; age at diagnosis; pathological tumour size and stage; tumour histology; tumour grade; presence of lymphovascular invasion; nodal status; and oestrogen receptor (ER), progesterone receptor (PR), and human epidermal growth factor receptor 2 (HER-2) gene amplification status. The data reporting criteria of ER, PR, HER-2, and Ki-67 were previously described. ${ }^{9}$ Cases were considered positive for ER and PR expression if the nuclei of at least $1 \%$ of the tumour cells were stained. High Ki-67 expression was defined as immunostaining in more than $14 \%$ of the tumour cells.

\section{Measurement and Recording of Tumour Quadrant and Tumour-Nipple Distance}

During surgery, it is the standard routine protocol at the Department of Breast Surgery, West China Hospital of Sichuan University to measure and record the tumour's location within the breast and the tumour-nipple distance (in centimetres). The tumour locations were recorded in clock position or as beneath the nipple or peri-areolar area. The distance was measured radially from the nipple to the tumour's epicentre rather than edge by a ruler to obviate confounders resulting from tumour size variations. The specimens are then routinely dissected. However, for patients who underwent breast-conserving surgery, we measured the distance on the body with the patients lying down. These data were prospectively archived and retrospectively retrieved.

\section{Statistical Analysis}

Comparisons of the clinical and pathologic features of patients with versus those without axillary lymph node metastasis were performed using analysis of variance with Pearson's $\chi^{2}$ test and $t$-test. We identified all clinically significant parameters (Table 1 ) in the multivariate analysis. Multivariate logistic regression was used to measure the relationship between various predictive variables and axillary lymph node involvement. All tests were two-tailed and $p$-values $<0.05$ were considered significant. The statistical analysis was performed using SPSS version 16.0 software (SPSS Inc., Chicago, IL, USA).

\section{Results}

\section{Patient Characteristics}

Among the 961 patients with breast cancer who were diagnosed and treated between January 2000 and April 2016, 122 were excluded for the following reasons: male sex $(n=6)$, nodal status unavailability $(\mathrm{n}=12)$, receipt of neoadjuvant chemotherapy before surgery $(n=46)$, presence of multifocal 
Table I Patient and Tumor Characteristics Comparisons Between Patients with and without Axillary Lymph Node Metastasis

\begin{tabular}{|c|c|c|c|c|}
\hline Characteristics & Overall $(n=847)$ & $\begin{array}{l}\text { Negative Axillary } \\
\text { Involvement }(n=425)\end{array}$ & $\begin{array}{l}\text { Positive Axillary } \\
\text { Involvement ( } n=422)\end{array}$ & $p$-value \\
\hline Age at diagnosis (mean $\pm \mathrm{SD}$ ) & $48.30 \pm 10.42$ & $49.10 \pm 10.39$ & $47.50 \pm|0.4|$ & 0.026 \\
\hline Tumor size, cm (mean $\pm \mathrm{SD}$ ) & $2.97 \pm 1.74$ & $2.56 \pm 1.18$ & $3.36 \pm 2.08$ & $<0.001$ \\
\hline Tumor-nipple distance, $\mathrm{cm}$ (mean $\pm \mathrm{SD})$ & $3.01 \pm 2.15$ & $3.41 \pm 2.18$ & $2.76 \pm 2.07$ & $<0.001$ \\
\hline $\mathrm{T}$ classification & & & & $<0.001$ \\
\hline TI & $28.69 \%(243 / 847)$ & $34.59 \%(147 / 425)$ & $22.75 \%(96 / 422)$ & \\
\hline $\mathrm{T} 2$ & $51.36 \%(435 / 847)$ & $48.71 \%(207 / 425)$ & $54.03 \%(228 / 422)$ & \\
\hline T3 & $6.38 \%(54 / 847)$ & $2.12 \%(9 / 425)$ & $10.66 \%(45 / 422)$ & \\
\hline T4 & $3.42 \%(29 / 847)$ & $2.59 \%(11 / 425)$ & $4.27 \%(18 / 422)$ & \\
\hline Tx & $7.56 \%(64 / 847)$ & $9.18 \%(39 / 425)$ & $5.92 \%(25 / 422)$ & \\
\hline Unknown & $2.60 \%(22 / 847)$ & $2.82 \%(12 / 425)$ & $2.37 \%(10 / 422)$ & \\
\hline ER status & & & & 0.876 \\
\hline Negative & $35.77 \%(303 / 847)$ & $36.47 \%(155 / 425)$ & $35.07 \%(148 / 422)$ & \\
\hline Positive & $62.46 \%(529 / 847)$ & $61.65 \%(262 / 425)$ & $63.27 \%(267 / 422)$ & \\
\hline Unknown & $1.77 \%(15 / 847)$ & I.88\% (8/425) & $1.66 \%(7 / 422)$ & \\
\hline PR status & & & & 0.957 \\
\hline Negative & $36.72 \%(311 / 847)$ & $36.24 \%(154 / 425)$ & $37.2 \%(157 / 422)$ & \\
\hline Positive & $61.39 \%(520 / 847)$ & $61.88 \%(263 / 425)$ & $60.9 \%(257 / 422)$ & \\
\hline Unknown & $1.89 \%(16 / 847)$ & $1.88 \%(8 / 425)$ & $1.9 \%(8 / 422)$ & \\
\hline HER-2 status & & & & 0.355 \\
\hline Negative & $74.14 \%(628 / 847)$ & $73.65 \%(3 \mid 3 / 425)$ & $74.64 \%(315 / 422)$ & \\
\hline Positive & $13.46 \%(114 / 847)$ & $12.71 \%(54 / 425)$ & $14.22 \%(60 / 422)$ & \\
\hline Uncertain & $8.74 \%(74 / 847)$ & $10.35 \%(44 / 425)$ & $7.11 \%(30 / 422)$ & \\
\hline Unknown & $3.66 \%(3 I / 847)$ & $3.29 \%(14 / 425)$ & $4.03 \%(17 / 422)$ & \\
\hline Ki-67 expression & & & & 0.155 \\
\hline High expression & $60.09 \%(509 / 847)$ & $61.65 \%(262 / 425)$ & $58.53 \%(247 / 422)$ & \\
\hline Not high expression & $18.42 \%(156 / 847)$ & $19.53 \%(83 / 425)$ & $17.3 \%(73 / 422)$ & \\
\hline Unknown & $21.49 \%(182 / 847)$ & $18.82 \%(80 / 425)$ & $24.17 \%(102 / 422)$ & \\
\hline Lymphovascular invasion & & & & $<0.001$ \\
\hline Yes & $2.48 \%(2 \mathrm{I} / 847)$ & $0.47 \%(2 / 425)$ & $4.5 \%(19 / 422)$ & \\
\hline No & $97.52 \%(826 / 847)$ & $99.53 \%(423 / 425)$ & $95.5 \%(403 / 422)$ & \\
\hline Tumor location & & & & $<0.001$ \\
\hline 12 or 6 o'clock & $12.28 \%(104 / 847)$ & $13.18 \%(56 / 425)$ & $11.37 \%(48 / 422)$ & \\
\hline Inner quadrants & $24.32 \%(206 / 847)$ & $30.59 \%(130 / 425)$ & $18.01 \%(76 / 422)$ & \\
\hline Outer quadrants & $55.02 \%(466 / 847)$ & $49.41 \%(210 / 425)$ & $60.66 \%(256 / 422)$ & \\
\hline Beneath nipple/peri areolar & $4.25 \%(36 / 847)$ & $1.88 \%(8 / 425)$ & $6.64 \%(28 / 422)$ & \\
\hline Unknown & $4.13 \%(35 / 847)$ & $4.94 \%(2 \mathrm{I} / 425)$ & $3.32 \%(14 / 422)$ & \\
\hline
\end{tabular}

Abbreviations: SD, standard deviation; ER, estrogen receptor; PR, progesterone receptor; HER-2, human epidermal growth factor receptor 2.

or multicentric tumours $(n=29)$, recurrence $(n=6)$, prior history of breast surgery $(n=11)$, Paget's disease $(n=2)$, metastasis $(n=8)$, and tumour fixed to the chest wall $(n=2)$. Eight patients had bilateral disease, and each cancer was staged according to lymph node involvement in the left and right axilla, respectively. Ultimately, a total of 847 breast cancers (839 patients) met the eligibility criteria and were included in the statistical analysis. The overall rate of axillary involvement was $49.82 \%$ (422/847), and the clinicopathologic features of the included cases are summarised in Table 1.

\section{Proximity to the Nipple}

The average tumour-nipple distance was $3.01 \pm 2.15 \mathrm{~cm}$. Among those with positive axillary lymph nodes, the tumour-nipple distance was $2.76 \pm 2.07 \mathrm{~cm}$, which was significantly smaller than that of patients with negative 
axillary lymph nodes $(p<0.001$; Table 1$)$. We observed the distribution of tumour-nipple distances at 1-cm intervals regardless of axillary nodal status. We further stratified the tumours into two categories by their proximity to the nipple, ie, $\leq 30 \mathrm{~mm}$ and $>30 \mathrm{~mm}$. The rates of axillary nodal involvement were statistically different between the two groups $\left(\chi^{2}=4.540, p=0.033\right)$. More specifically, the closer the proximity of the tumour to the nipple, the higher the rate of axillary involvement (Table 2). Further, the same relationship was noted between tumour-nipple distance and axillary involvement in the upper outer quadrant (Table 3). Moreover, we divided the tumours into those $\leq 30 \mathrm{~mm}$ (the median) and those $>30 \mathrm{~mm}$ to the nipple in the logistic regression analysis. As expected, the tumour-nipple distance was an independent risk factor for axillary involvement (odds ratio, 0.561; 95\% confidence interval, 0.377-0.835; $p=0.004$ ) (Table 4).

\section{Location Within the Breast}

We compared the nodal involvement of the patients by tumour location: 12 or 6 o'clock, inner quadrants, outer quadrants, and beneath the nipple/periareolar area. As shown in Table 1, the rates of axillary nodal involvement were statistically different among tumour location within the breast $(p<0.001)$. However, tumour location did not affect node status as confirmed by logistic regression (Table 4).

\section{Discussion}

This study aimed to investigate whether the breast cancer tumour's proximity to the nipple or its location within the breast is associated with the incidence of axillary lymph node involvement. This study on the tumour-nipple distance includes the largest sample size of all related studies to date.

Our result indicated that axillary lymph node involvement was associated with a smaller tumour-nipple distance, a finding that is in accordance with those of two existing publications. Ansari et al retrospectively reviewed tumour-nipple distances from the ultrasounds of 233 breast cancers at Mayo Clinic and concluded that each $1-\mathrm{cm}$ decrease in the distance from the nipple was associated with a $23 \%$ increase in the likelihood of lymph node positivity $(p=0.003) .{ }^{10}$ Based on 401 patients, Torstenson et al added tumour-nipple distance as a variable in established nomograms and significantly improved the prediction of nodal positivity. ${ }^{11}$ However, there were also contradictory reports. Lewis et al retrospectively reviewed 285 patients and concluded that tumour proximity to the nipple (obtained from mammography) was not associated with axillary lymph node metastasis. ${ }^{12}$ In recent years, a retrospective study of 266 patients revealed null differences in pathological $\mathrm{N}$ stages between an MRI-based group of short tumour-nipple distance $(<2.0 \mathrm{~cm})$ and a group of long tumour-nipple distance $(\geq 2.0 \mathrm{~cm}){ }^{13}$ The methods for distance measurement for these existing studies were all imaging modalities, for which technical defects are inevitable and might be a source of discrepancies. ${ }^{14}$ For example, the pressure from an ultrasound probe during the examination is uncontrollable, resulting in weak repeatability. In addition, different imaging modalities have unique systems that do not allow direct comparisons with any other methods. In our study, the tumour-nipple distance was visualised and measured objectively during surgery, which ensured that the distance measuring system did not have the aforementioned

Table 2 Distribution of Tumor-Nipple Distance Among Patients with and without Axillary Lymph Node Metastasis $\left(C h i^{2}=4.540\right.$, $p=0.033$ )

\begin{tabular}{|l|l|l|l|}
\hline Status of Axillary Lymph Nodes & $\leq \mathbf{3 0} \mathbf{~ m m}$ & $>\mathbf{3 0} \mathbf{~ m m}$ & Total \\
\hline Negative & $46.72 \%(2 / 4 / 458)$ & $56.85 \%(83 / 146)$ & $49.17 \%(297 / 604)$ \\
Positive & $53.28 \%(244 / 458)$ & $43.15 \%(63 / 146)$ & $50.83 \%(307 / 604)$ \\
\hline
\end{tabular}

Table 3 Distribution of Tumor-Nipple Distance Among Patients with and without Axillary Lymph Node Metastasis in Upper Outer Quadrant $\left(C h i^{2}=4.244, p=0.039\right)$

\begin{tabular}{|l|l|l|l|}
\hline Status of Axillary Lymph Nodes & $\leq \mathbf{3 0} \mathbf{~ m m}$ & $\mathbf{> 3 0} \mathbf{~ m m}$ & Total \\
\hline Negative & $42.22 \%(57 / / 35)$ & $56.47 \%(48 / 85)$ & $47.73 \%(105 / 220)$ \\
Positive & $57.78 \%(78 / / 35)$ & $43.53 \%(37 / 85)$ & $52.27 \%($ (II5/220) \\
\hline
\end{tabular}


Table 4 Multivariate Logistic Regression of Factors Associated with Axillary Lymph Node Involvement

\begin{tabular}{|c|c|c|}
\hline Variables & OR $(95 \% \mathrm{CI})$ & $p$-value \\
\hline \multicolumn{3}{|l|}{ Age at diagnosis } \\
\hline$\leq 40$ & 1.00 (ref) & \\
\hline $40-60$ & $0.576(0.344,0.966)$ & 0.036 \\
\hline$>60$ & $0.691(0.352,1.360)$ & 0.285 \\
\hline \multicolumn{3}{|l|}{ Tumor-nipple distance } \\
\hline$\leq 30 \mathrm{~mm}$ & 1.00 (ref) & \\
\hline$>30 \mathrm{~mm}$ & $0.56 \mathrm{I}(0.377,0.835)$ & 0.004 \\
\hline \multicolumn{3}{|l|}{ T stage } \\
\hline I & 1.00 (ref) & \\
\hline 2 & $1.573(1.045,2.369)$ & 0.030 \\
\hline $3-4$ & $1.848(0.892,4.119)$ & 0.133 \\
\hline \multicolumn{3}{|l|}{ ER status } \\
\hline Positive & 1.00 (ref) & \\
\hline Negative & $0.722(0.4|5| .255)$, & 0.248 \\
\hline \multicolumn{3}{|l|}{ PR status } \\
\hline Positive & 1.00 (ref) & \\
\hline Negative & I.02I (0.602, I.733) & 0.939 \\
\hline \multicolumn{3}{|l|}{ HER-2 status } \\
\hline Positive & 1.00 (ref) & \\
\hline Negative & I.142 (0.675, I.932) & 0.621 \\
\hline Uncertain & $0.858(0.399,1.847)$ & 0.695 \\
\hline \multicolumn{3}{|l|}{ Ki-67 expression } \\
\hline High & 1.00 (ref) & \\
\hline Low & $0.932(0.585,1.486)$ & 0.768 \\
\hline \multicolumn{3}{|l|}{ Lymphovascular invasion } \\
\hline Yes & $\mathrm{I} .00$ (ref) & \\
\hline No & $0.083(0.01 \mathrm{I}, 0.657)$ & 0.018 \\
\hline \multicolumn{3}{|l|}{ Tumor location(quadrant) } \\
\hline 12 or 6 o'clock & $\mathrm{I} .00$ (ref) & \\
\hline Inner quadrants & $0.684(0.356,1.313)$ & 0.254 \\
\hline Outer quadrants & I.540 (0.849, 2.794) & 0.155 \\
\hline Beneath nipple/peri areolar & $2.284(0.749,6.963)$ & 0.147 \\
\hline
\end{tabular}

Abbreviations: ER, estrogen receptor; PR, progesterone receptor; HER-2, human epidermal growth factor receptor 2 .

defects. The tumour-nipple distance results of recent studies are summarised in Table 5.

The association between tumour-nipple distance and involvement of the nipple-areolar complex (NAC) has been extensively explored, and a smaller tumour-nipple distance was reportedly associated with a higher risk of NAC involvement. ${ }^{17-20}$ Furthermore, in one study, the incidence of axillary lymph node metastasis was significantly higher in patients with nipple involvement (36.71\%) than in patients with unifocal tumours $(9.76 \%))^{21}$ Such correlations might explain the association between tumour-nipple distance and axillary status. The mechanism may be related to the lymphatic drainage system of the breast. However, anatomical research and experiments are needed to confirm this hypothesis.

An association between tumour location (by quadrant) and axillary lymph node involvement was lacking in this study. This was supported by results of previous retrospective studies. ${ }^{8,12}$ A recent study examined 7856 Korean patients with nodal-positive invasive ductal carcinoma and investigated the prognostic implication of tumour location according to molecular subtype. ${ }^{22}$ The $90-$ month follow-up showed significantly worse survival of patients with lower inner located tumours, which are only significant in cases of HER-2 overexpression and triplenegative subtypes. Furthermore, other studies also reported poorer prognosis in patients with tumours located in the lower inner quadrant. ${ }^{23}$ This phenomenon was probably because tumours in the lower inner quadrant have better access to the internal mammary lymph nodes. However, the reason why tumours in the upper outer quadrant, which have probable better anatomical access to the axillary lymph nodes, do not affect the incidence of axillary involvement requires further study.

The current study has its own limitations. First, breast size varies among patients and may affect the measured distance. Such data were not included in statistical analysis because of a lack of information. Nonetheless, the breast sizes of Asian women are generally smaller and less variable than those of women from Western countries, decreasing the likelihood of potential imperfections. Second, outcomes such as local recurrence and survival were not analysed; thus, future studies with more comprehensive data are required. Third, the logistic regression model does not allow for full interpretation of the pattern in cases of axillary node positivity, possibly because some other influential variables such as family history were not included among the interpreted variables. Therefore, the inclusion of more exhaustive variables would be ideal to improve the current model.

In conclusion, the current study with a large sample size provides well-grounded evidence that proximity from the tumour to the nipple is a risk factor of axillary lymph node involvement in patients with breast cancer. These results will provide assistance in surgical decisionmaking, especially in enigmatic scenarios such as "suspected metastasis" to the sentinel lymph node on a pathological report. However, prospective multicentre 
Table 5 Studies on Distance from Tumor and the Anatomical Landmarks of the Breast

\begin{tabular}{|c|c|c|c|c|c|c|c|c|}
\hline $\begin{array}{l}\text { First } \\
\text { Author }\end{array}$ & $\begin{array}{l}\text { Study } \\
\text { Design }\end{array}$ & $\begin{array}{l}\text { Sample } \\
\text { Size }\end{array}$ & $\begin{array}{l}\text { Anatomical } \\
\text { Landmark }\end{array}$ & $\begin{array}{l}\text { Factors That } \\
\text { are } \\
\text { Associated } \\
\text { with } \\
\text { Distance }\end{array}$ & $\begin{array}{l}\text { Factors That are } \\
\text { Not Associated } \\
\text { with Distance }\end{array}$ & $\begin{array}{l}\text { Method of } \\
\text { Distance } \\
\text { Measurement } \\
\text { (Imaging } \\
\text { Modality) }\end{array}$ & $\begin{array}{l}\text { Distance } \\
\text { Stratification } \\
(\mathrm{mm})\end{array}$ & $\begin{array}{l}\text { Overall } \\
\text { Rate of } \\
\text { Axillary } \\
\text { Involvement }\end{array}$ \\
\hline Ansari $B^{10}$ & Retrospective & 230 & Skin surface & Nodal status & & Ultrasound & Each I & $24.03 \%$ \\
\hline Ansari $B^{10}$ & Retrospective & 230 & Nipple & Nodal status & & Ultrasound & Each 10 & $24.03 \%$ \\
\hline $\begin{array}{l}\text { Cunningham } \\
\mathrm{JE}^{8}\end{array}$ & Retrospective & 209 & Skin surface & Nodal status & & Ultrasound & $\begin{array}{l}\leq 14 \text { vs }>14 \\
\text { continuous }\end{array}$ & $29.19 \%$ \\
\hline Eom $\mathrm{YH}^{14}$ & Retrospective & 891 & Skin surface & Nodal status & $\begin{array}{l}\text { Ipsilateral } \\
\text { recurrence; } \\
\text { Recurrence-free } \\
\text { survival }\end{array}$ & Ultrasound & $<3$ vs $\geq 3$ & $32.32 \%$ \\
\hline Kim WH $H^{15}$ & Retrospective & 1102 & Chest wall & $\begin{array}{l}\text { ER status; } \\
\text { Nodal status }\end{array}$ & & MRI & $\begin{array}{l}<3 \text { vs } \geq 3 \\
\text { continuous }\end{array}$ & $23.41 \%$ \\
\hline Lewis $\mathrm{El}^{12}$ & Retrospective & 285 & Nipple & & Nodal status & Mammography & NA & $38.25 \%$ \\
\hline Lewis $\mathrm{El}^{12}$ & Retrospective & 285 & Skin surface & & Nodal status & Ultrasound & $\leq 10$ vs $>10$ & $38.25 \%$ \\
\hline Ryu JM ${ }^{13}$ & Retrospective & 265 & Nipple & & $\begin{array}{l}\text { Nodal status; } \\
\text { Disease-free survival; } \\
\text { Local recurrence- } \\
\text { free survival }\end{array}$ & MRI & $<20$ vs $\geq 20$ & $26.42 \%$ \\
\hline Stallard $S^{16}$ & Retrospective & 220 & Nipple & $\begin{array}{l}\text { Local } \\
\text { recurrence }\end{array}$ & & Mammography & $<40$ vs $\geq 40$ & $-^{\mathrm{a}}$ \\
\hline $\begin{array}{l}\text { Torstenson } \\
T^{\prime \prime}\end{array}$ & Retrospective & 401 & Skin surface & Nodal status & & Ultrasound & $\begin{array}{l}\leq 10 \text { vs }>10 \\
\text { each } 10\end{array}$ & $19.70 \%$ \\
\hline $\begin{array}{l}\text { Torstenson } \\
T^{\prime \prime}\end{array}$ & Retrospective & 401 & Nipple & Nodal status & & Ultrasound & $\begin{array}{l}\leq 20,20 \sim 50 \\
>50 \text {; each } 10\end{array}$ & $19.70 \%$ \\
\hline $\begin{array}{l}\text { The present } \\
\text { study }\end{array}$ & Retrospective & 847 & Nipple & Nodal status & & $\begin{array}{l}\text { Intraoperative } \\
\text { pathological } \\
\text { measurement }\end{array}$ & $\begin{array}{l}\leq 20,20 \sim 50 \\
>50 \\
\text { continuous }\end{array}$ & $49.82 \%$ \\
\hline
\end{tabular}

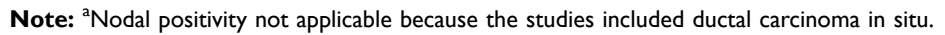

Abbreviations: NA, not available; ER, estrogen receptor.

studies with larger sample size are needed to confirm this conclusion, while further exploratory studies are needed to increase our understanding of the mechanism of this phenomenon.

\section{Conclusions}

Our study findings indicated that tumour-nipple distance, not tumour location within the breast, can be adopted as a valid factor for predicting axillary lymph node involvement and assist in surgical decision-making and therapy planning.

\section{Data Sharing Statement}

The datasets analysed during the current study available from the corresponding author on reasonable request.

\section{Ethics Approval and Consent to Participate}

This study was approved by the West China Hospital Research Ethics Committee (No. 2017[250]), which waived the need for informed consent due to its retrospective nature. 


\section{Funding}

This study is supported by the Program of the Science and Technology Bureau of Sichuan (2020YJ0293) and Chengdu Science and Technology Bureau (2019-YF0501082-SN).

\section{Disclosure}

The authors declare no potential conflicts of interest.

\section{References}

1. Lu YS, Kuo SH, Huang CS. Recent advances in the management of primary breast cancers. J Formos Med Assoc. 2004;103(8):579-598.

2. Assing MA, Patel BK, Karamsadkar N, et al. A comparison of the diagnostic accuracy of magnetic resonance imaging to axillary ultrasound in the detection of axillary nodal metastases in newly diagnosed breast cancer. Breast J. 2017;23(6):647-55.

3. Hernández A. Axillary dissection vs no axillary dissection in women with invasive breast cancer and sentinel node metastasis. JAMA. 2011;305(6):569-575. doi:10.1001/jama.2011.90

4. Suami H, Pan WR, Taylor GI. Historical review of breast lymphatic studies. Clin Anat. 2009;22(5):531-536. doi:10.1002/ca.20812

5. Pavlista D, Eliska O. Cutaneous and subcutaneous lymphatic drainage of the breast. Lymphology. 2005;38(2):92-102.

6. Suami H, Pan WR, Mann GB, Taylor GI. The lymphatic anatomy of the breast and its implications for sentinel lymph node biopsy: a human cadaver study. Ann Surg Oncol. 2008;15(3):863-871. doi:10.1245/s10434-007-9709-9

7. Li ML, Hegemann NS, Manapov F, et al. Prefraction displacement and intrafraction drift of the prostate due to perineal ultrasound probe pressure. Strahlenther Onkol. 2017;1-7.

8. Cunningham JE, Jurj AL, Oman L, Stonerock AE, Nitcheva DK, Cupples TE. Is risk of axillary lymph node metastasis associated with proximity of breast cancer to the skin? Breast Cancer Res Treat. 2006;100(3):319-328. doi:10.1007/s10549-006-9256-2

9. Yang JQ, Tang SL, Zhou YT, et al. Prognostic implication of the primary tumor location in early-stage breast cancer: focus on lower inner zone. Breast Cancer. 2018;25(1):100-107. doi:10.1007/s12282017-0797-5

10. Ansari B, Morton MJ, Adamczyk DL, et al. Distance of breast cancer from the skin and nipple impacts axillary nodal metastases. Ann Surg Oncol. 2011;18(11):3174-3180. doi:10.1245/s10434-011-1957-z

11. Torstenson T, Shah-Khan MG, Hoskin TL, et al. Novel factors to improve prediction of nodal positivity in patients with clinical T1/T2 breast cancers. Ann Surg Oncol. 2013;20(10):3286-3293. doi:10. 1245/s10434-013-3110-7
12. Lewis EI, Ozonoff A, Nguyen CP, Kim M, Slanetz PJ. Breast cancer close to the nipple: does this increase the risk of nodal metastasis at diagnosis? Can Assoc Radiol J. 2011;62(3):209-214. doi:10.1016/j. carj.2010.03.007

13. Ryu JM, Nam SJ, Kim SW, et al. Feasibility of nipple-sparing mastectomy with immediate breast reconstruction in breast cancer patients with tumor-nipple distance less than $2.0 \mathrm{~cm}$. World J Surg. 2016;40(8):2028-2035. doi:10.1007/s00268-016-3487-0

14. Eom YH, Kim EJ, Chae BJ, Song BJ, Jung SS. The distance between breast cancer and the skin is associated with axillary nodal metastasis. J Surg Oncol. 2015;111(7):824-828. doi:10.1002/jso.23898

15. Kim WH, Han W, Chang JM, Cho N, Park IA, Moon WK. Location of triple-negative breast cancers: comparison with estrogen receptorpositive breast cancers on MR imaging. PloS one. 2015;10:e116344

16. Stallard S, Hole DA, Purushotham AD, Hiew LY, Mehanna H, Cordiner C, et al. Ductal carcinoma in situ of the breast-among factors predicting for recurrence, distance from the nipple is important. Eur J Surg Oncol. 2001;27:373-377

17. Machida Y, Shimauchi A, Igarashi T, Hoshi K, Fukuma E. Preoperative breast MRI: reproducibility and significance of findings relevant to nipple-areolar complex involvement. Breast Cancer. 2018;25(4):456-463. doi:10.1007/s12282-018-0845-9

18. Dent BL, Miller JA, Eden DJ, Swistel A, Talmor M. Tumor-to-nipple distance as a predictor of nipple involvement: expanding the inclusion criteria for nipple-sparing mastectomy. Plast Reconstr Surg. 2017;140(1):1e-8e. doi:10.1097/PRS.0000000000003414

19. Giannini V, Bianchi V, Carabalona S, et al. MRI to predict nippleareola complex (NAC) involvement: an automatic method to compute the 3D distance between the NAC and tumor. J Surg Oncol. 2017;116(8):1069-1078. doi:10.1002/jso.24788

20. Mariscotti G, Durando M, Houssami N, et al. Preoperative MRI evaluation of lesion-nipple distance in breast cancer patients: thresholds for predicting occult nipple-areola complex involvement. Clin Radiol. 2018;73(8):735-743. doi:10.1016/j.crad.2018.03.008

21. Cakir M, Tekin A, Kücükkartallar T, et al. Axillary lymph node status in multicentric breast tumors and breast tumors with nipple involvement. Breast Care. 2012;7(5):394-396. doi:10.1159/000343299

22. Lim ST, Choi JE, Kim SJ, et al. Prognostic implication of the tumor location according to molecular subtypes in axillary lymph node-positive invasive ductal cancer in a Korean population. Breast Cancer Res Treat. 2016;156(3):473-483. doi:10.1007/s10549-016-3771-6

23. Wu SG, Zhou J, Ren YF, et al. Tumor location is a prognostic factor for survival of Chinese women with T1-2N0M0 breast cancer. Int J Surg. 2014;12(5):394-398. doi:10.1016/j.jjsu.2014.03.011

\section{Publish your work in this journal}

Cancer Management and Research is an international, peer-reviewed open access journal focusing on cancer research and the optimal use of preventative and integrated treatment interventions to achieve improved outcomes, enhanced survival and quality of life for the cancer patient.
The manuscript management system is completely online and includes a very quick and fair peer-review system, which is all easy to use. Visit http://www.dovepress.com/testimonials.php to read real quotes from published authors. 